\title{
Evaluation of Chronic Gastritis in Endoscopic Antral Biopsies Using the Up-dated Sydney System
}

\author{
Hayfa A. Hussein \\ Department of Pathology, Al-Salam Teaching Hospital, Mosul-Iraq \\ Correspondence:hayfaa517@gmail.com
}

(Ann Coll Med Mosul 2019; 41 (2):95-105).

Received: $16^{\text {th }}$ Feb. 2019; Accepted: $15^{\text {th }}$ May 2019.

\begin{abstract}
Objectives: To evaluate the histological parameters of chronic gastritis in endoscopic antral biopsies, to grade them according to the up-dated Sydney system and to compare the obtained results with those of others.

Methods: From the 1st of July 2018 to the end of December 2018,100 endoscopic antral gastric biopsies were submitted to the Histopathology Unit in Al-Salam Teaching Hospital in Mosul, obtained from patients complaining of different clinical symptoms and referred for upper gastrointestinal endoscopy. Biopsies were assessed for the histological parameters of chronic gastritis and were also graded using the visual analogue scale of the up- dated Sydney system.

Results: The 100 biopsies belonged to 42 males and 58 females ranging from 9-85 years old with a mean of 42.7 years and a peak age incidence in the fourth decade. The commonest symptom was epigastric pain in $(46 \%)$ of cases. Antral gastritis was the major endoscopic finding in $(66 \%)$ of cases. All cases revealed mononuclear cell infiltration(100\%), followed by neutrophilic activity (84\%), glandular atrophy(22\%), intestinal metaplasia(14\%) and dysplasia(9\%). Helicobacter pylori (H. pylori) was detected in $(77 \%)$ of cases and a significant statistical association was found between $H$. pylori and each of: mononuclear cell infiltration $(P<0.001)$, neutrophilic activity $(P<0.001)$ and glandular atrophy $(P<0.05)$. while insignificant statistical association was observed between $H$. pylori and both intestinal metaplasia and dysplasia $(P>0.05)$.

Conclusion: Histopathological study of endoscopic antral gastric biopsy is of value in detection of $H$. pylori and various histological changes of chronic gastritis. A statistically significant association was found between $H$. pylori and each of : mononuclear cell infiltration, neutrophilic activity and glandular atrophy. Dysplasia is an important histological change in chronic gastritis that requires endoscopic follow up to rule out the possibility of gastric cancer, and it is advisable to be incorporated in the visual analogue scale of the updated Sydney system.
\end{abstract}

Keywords: chronic gastritis, antral biopsy, up-dated Sydney system.

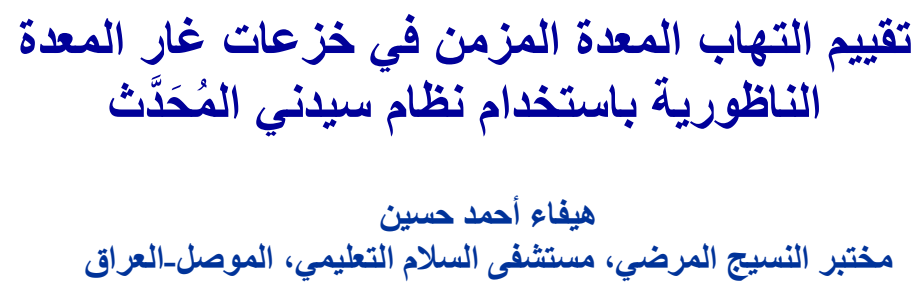

الخلاصة

الهدف من الدراسة: تهدف الدر اسة إلى تقييم المعايير النسيجية لالتهاب المعدة المزمن من خلال استحصال خزعات ناظورية لغار

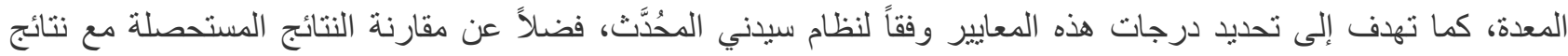
الدر اسات السابقة.

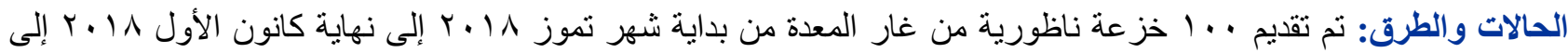

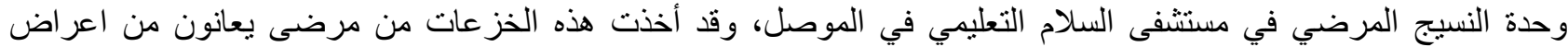


سريرية مختلفة وأُحيلو إلى تنظير الجهاز الهضمي العلوي. وقد تم تقييم الخزعات على وفق المعايير النسيجية لالتهاب المعدة

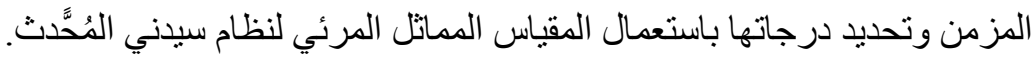

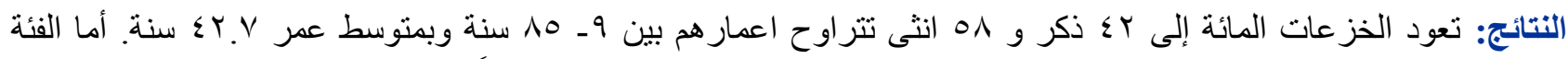

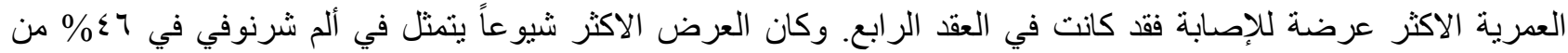

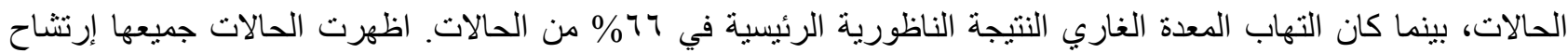

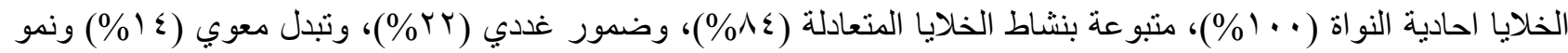

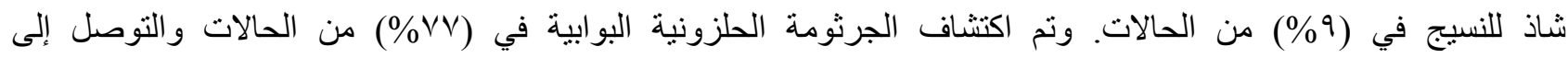

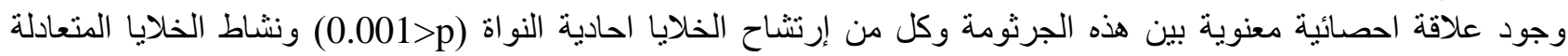

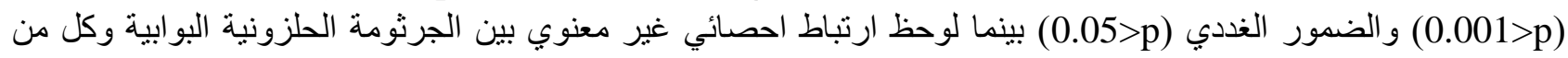

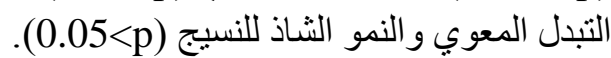

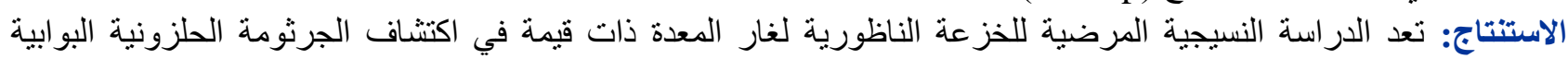

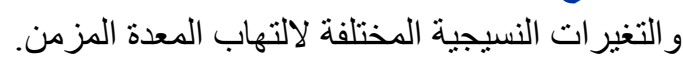

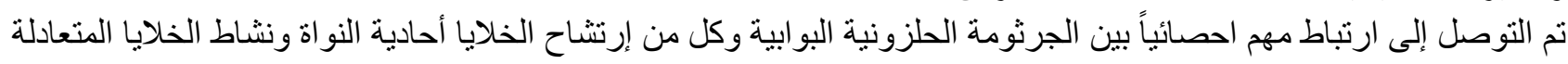
والضدمور الغدي.

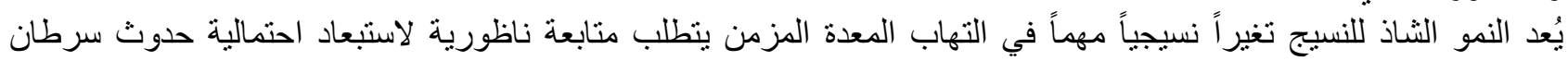

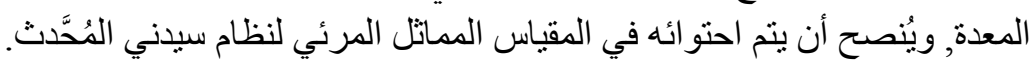

الكلمات المفتاحية: التهاب المعدة المزمن، خزعة غار المعدة، نظام سيدني المُحَدَّث.

\section{INTRODUCTION}

nflammation of gastric mucosa is the simple definition of gastritis ${ }^{1}$, and chronic gastritis is recognized by chronic inflammatory cell infiltration of the gastric mucosa, mainly plasma cells and lymphocytes (sometimes with lymphoid follicle formation), leading to eventual atrophy of the glandular epithelium and intestinal metaplasia which is strongly related to increased risk of gastric carcinoma ${ }^{2}$.

There are many etiological factors of chronic gastritis, however the most common cause is infection with the bacillus Helicobacter pylori ${ }^{3-5}$. which most often presents as antral gastritis and gastric biopsy generally demonstrates $H$. pylori as spiral-shaped or curved bacilli, concentrating within the superficial mucus of the surface epithelium and neck region of the glands ${ }^{6}$.

Gastritis was classified in different ways, however to avoid confusion, a system was proposed in 1991 for microscopic reporting of gastritis referred to as "The Sydney System" which included a spectrum of morphological, topographical and possible etiological factors of gastritis $^{7}$. The value of this system lies in grading of different histological parameters of chronic gastritis including: $H$. pylori density, mononuclear cell infiltration (as a sign of chronic inflammation), neutrophilic infiltration (as a sign of activity), glandular atrophy and intestinal metaplasia, using the visual analogue scale of the up-dated Sydney system ${ }^{8}$.

\section{AIMS OF THE STUDY}

To evaluate various histological parameters of chronic gastritis in endoscopic antral biopsies, to grade them according to the up-dated Sydney system, and to compare the obtained results with those of others.

\section{MATERIAL AND METHODS}

Over the period from the 1st of July 2018 to the end of December 2018, 100 endoscopic biopsy specimens were obtained from gastric antrum of patients complaining of different clinical symptoms referred for upper gastrointestinal endoscopy at AlSalam Teaching Hospital in Mosul. The clinical data concerning the presenting symptoms of patients were obtained from the submitted request forms.

Each biopsy specimen consisted of 2-3 tissue fragments, fixed in 10\% formalin, processed according to the standard histopathology techniques and stained with the routin hematoxylin-eosin stain, in addition to modified 
Giemsa stain for a proper demonstration of $H$. pylori?.

Sections were assessed for the histological parameters of chronic gastritis, together with grading of these parameters using the visual analogue scale of the up-dated Sydney system presented in Figure 1.
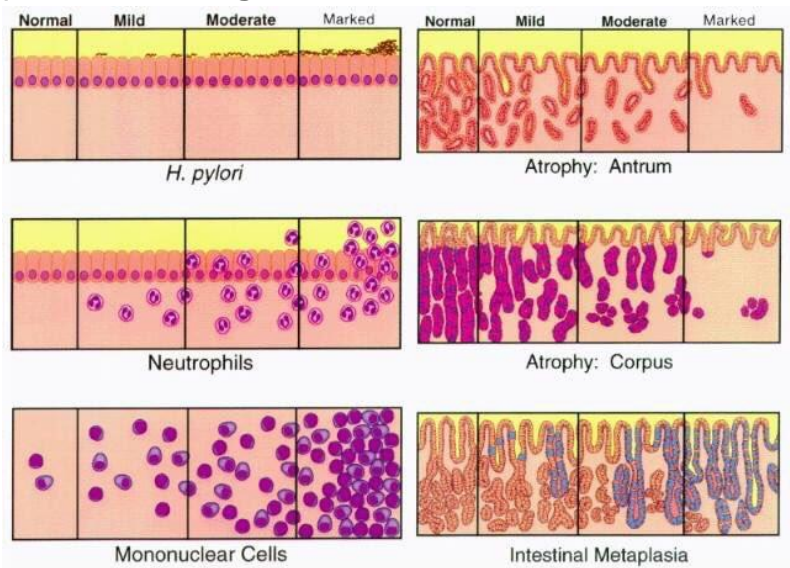

Figure 1: Visual analogue scale for grading of chronic gastritis: The Up-dated Sydney System ${ }^{8}$.

Results were statistically analyzed using Z-test of one proportion in which $P$-value $<0.05$ was regarded as a significant result.

\section{RESULTS}

The 100 endoscopic antral gastric biopsies were analyzed as follows:

\section{Distribution According to Age and Sex}

Patients were distributed over a wide age range from 9 to 85 years, with a mean of 42.7 years and a peak age incidence in the fourth decade.

There were 42 males and 58 females with a male to female ratio of 1: 1.3. Figure 2 .

\section{Clinical Symptoms}

The main complaint was epigastric pain in 46 (46\%) cases, followed by dyspepsia in $17(17 \%)$ cases, nausea and vomiting in $16(16 \%)$ cases and upper GIT bleeding in $10(10 \%)$ cases. The rest was presented with weight loss in $7(7 \%)$ cases and anemia in $4(4 \%)$ cases.

\section{Endoscopic Results}

Information regarding endoscopic findings was available in all cases including: isolated antral gastritis in $66(66 \%)$ cases, pangastritis in $13(13 \%)$ cases and gastritis limited to antrum and corpus in $11(11 \%)$ cases. Moreover antral gastritis was found to be associated with GU in $6(6 \%)$ cases and with DU in $4(4 \%)$ cases.

\section{Histological Findings}

The obtained results regarding various histological parameters found in tissue sections together with grading of these parameters according to the up-dated Sydney system are summarized in Table $\mathbf{1}$ and as follows.

1- Helicobacter pylori: It was demonstrated in $77(77 \%)$ cases out of 100 , including 30 males and 47 females with a male to female ratio of $1: 1.5$, and distributed among varying age groups with a higher rate of distribution in those 60 years and over. Figure 3 .

$H$. pylori was found in mild density in $39(50.6 \%)$ cases, moderate in $31(40.3 \%)$ cases while severe density was recorded in $7(9.1 \%)$ cases only. Figure 4 .

2-Mononuclear cell infiltration: Chronic inflammation represented by mononuclear cell infiltration was detected in all the $100(100 \%)$ cases Figure 5 , with varying drgrees where $17(17 \%)$ cases showing mild infiltrate, 56(56\%) cases moderate and $27(27 \%)$ cases were characterized by severe mononuclear cell infiltration, of which 4 cases have also demonstrated lymphoid follicles with germinal centers formation. Figure 6 .

3-Neutrophilic activity:Active inflammation represented by neutrophilic infiltration was detected in $84(84 \%)$ cases Figure 7 , and was graded as mild, moderate and severe in $31(36.9 \%), \quad 35(41.7 \%)$ and $18(21.4 \%)$ cases respectively.

4- Glandular atrophy:It was observed in $22(22 \%)$ cases Figure 8 , and was mild in $8(36.4 \%)$ cases, moderate in $11(50 \%)$ cases, while only $3(13.6 \%)$ cases have showed severe atrophic changes.

5- Intestinal metaplasia:It was found in only 14 (14\%) cases Figure 9 , out of which $7(50 \%)$ cases were mild, $4(28.6 \%)$ cases moderate and severe in $3(21.4 \%)$ cases.

6- Dysplasia:Besides the above, dysplasia was another histological finding observed in $9(9 \%)$ cases Figure 10 , and graded as mild in 5(55.6\%) cases, moderate in $2(22.2 \%)$ cases and severe in the last 2(22.2\%) cases.

Correlation between histological parameters and $H$. pylori: Among the 100 cases that showed mononuclear cellinfiltration, $H$. pylori was detected in $77(77 \%)$ cases, while undetected in $23(23 \%)$ 
cases. Moreover all the 27 cases with severe mononuclear cell infiltration including those with lymphoid follicles formation were shown to be positive for $H$. pylori.

Concerning the 84 cases with neutrophilic infiltration, $H$. pylori was positive in $77(91.7 \%)$ cases of them, while $7(8.3 \%)$ cases that showed neutrophilic activity were negative for $H$. pylori.

In relation to glandular atrophy which was seen in 22 cases, $H$. pylori was observed in $17(77.3 \%)$ cases, however it was not observed in the rest $5(22.7 \%)$ cases.

Out of the 14 cases in which intestinal metaplasia was noticed, $10(71.4 \%)$ cases displayed $H$. pylori, while the remaining 4 (28.6\%) cases did not.

Regarding the 9 cases of dysplasia, H. pylori was found in $6(66.7 \%)$ cases, while it was not found in the other $3(33.3 \%)$ cases.

Statistically, results were very highly significant regarding the association of $H$. pylori with both mononuclear cell infiltration and neutrophilic activity with P-value $=0.000$. The result was also significant in relation to $H$. pylori and glandular atrophy with $\mathrm{P}$-value $=0.011$. However results were statistically not significant regarding the association of $H$. pylori with both intestinal metaplasia $(P=0.109)$ and dysplasia $(P=0.317)$. Table 2 .

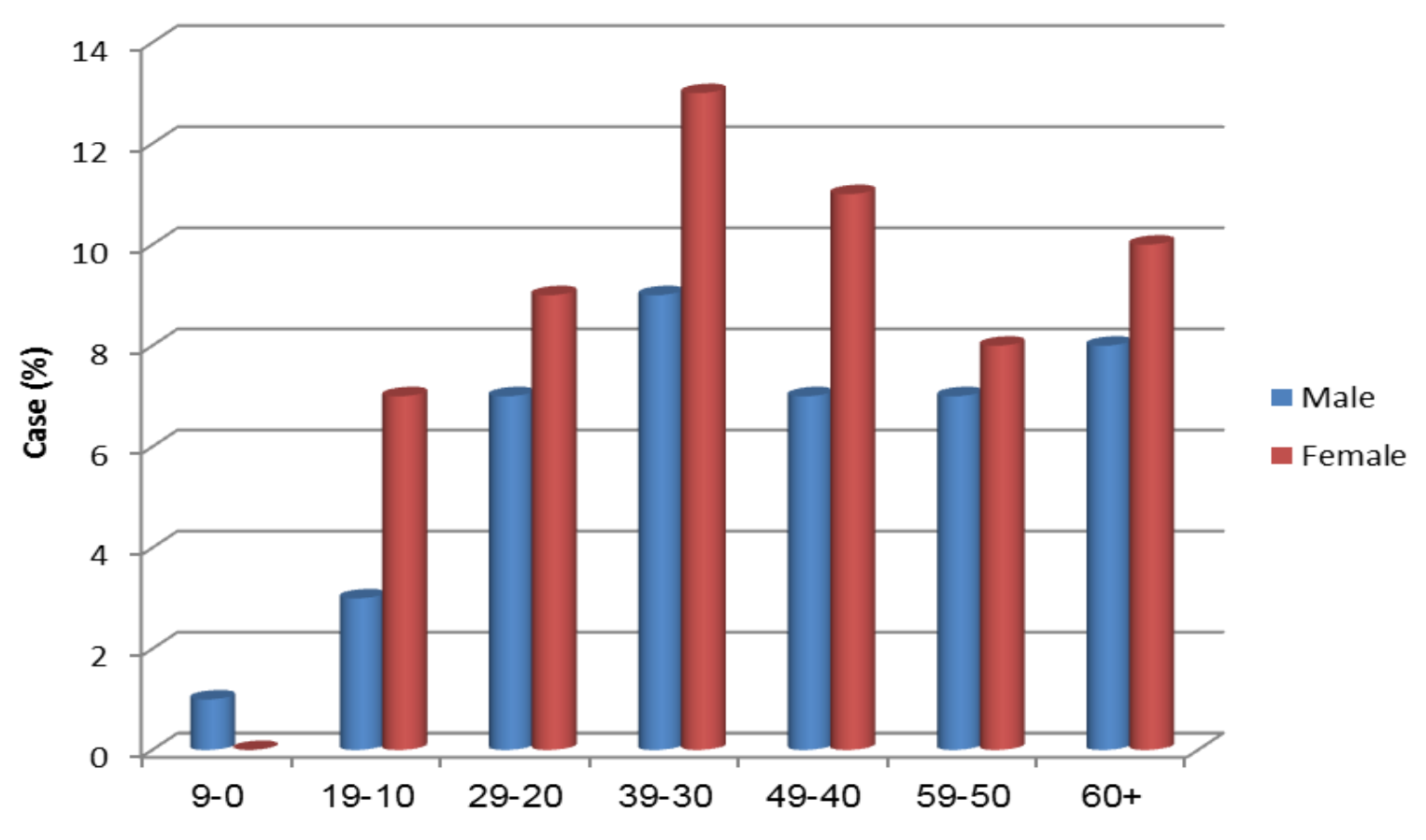

Figure 2: Distribution of patients according to age and sex 
Table 1: Grading of histological parameters of chronic gastritis.

\begin{tabular}{ccccc}
\hline Parameters & $\begin{array}{c}\text { No. of } \\
\text { cases }\end{array}$ & Mild & Moderate & Severe \\
\hline H. pylori & 77 & $39(50.6 \%)$ & $31(40.3 \%)$ & $7(9.1 \%)$ \\
Mononuclear cell & 100 & $17(17 \%)$ & $56(56 \%)$ & $27(27 \%)$ \\
$\begin{array}{c}\text { infiltration } \\
\text { Neutrophilic activity }\end{array}$ & 84 & $31(36.9 \%)$ & $35(41.7 \%)$ & $18(21.4 \%)$ \\
Glandular atrophy & 22 & $8(36.4 \%)$ & $11(50 \%)$ & $3(13.6 \%)$ \\
Intestinal metaplasia & 14 & $7(50 \%)$ & $4(28.6 \%)$ & $3(21.4 \%)$ \\
\hline
\end{tabular}

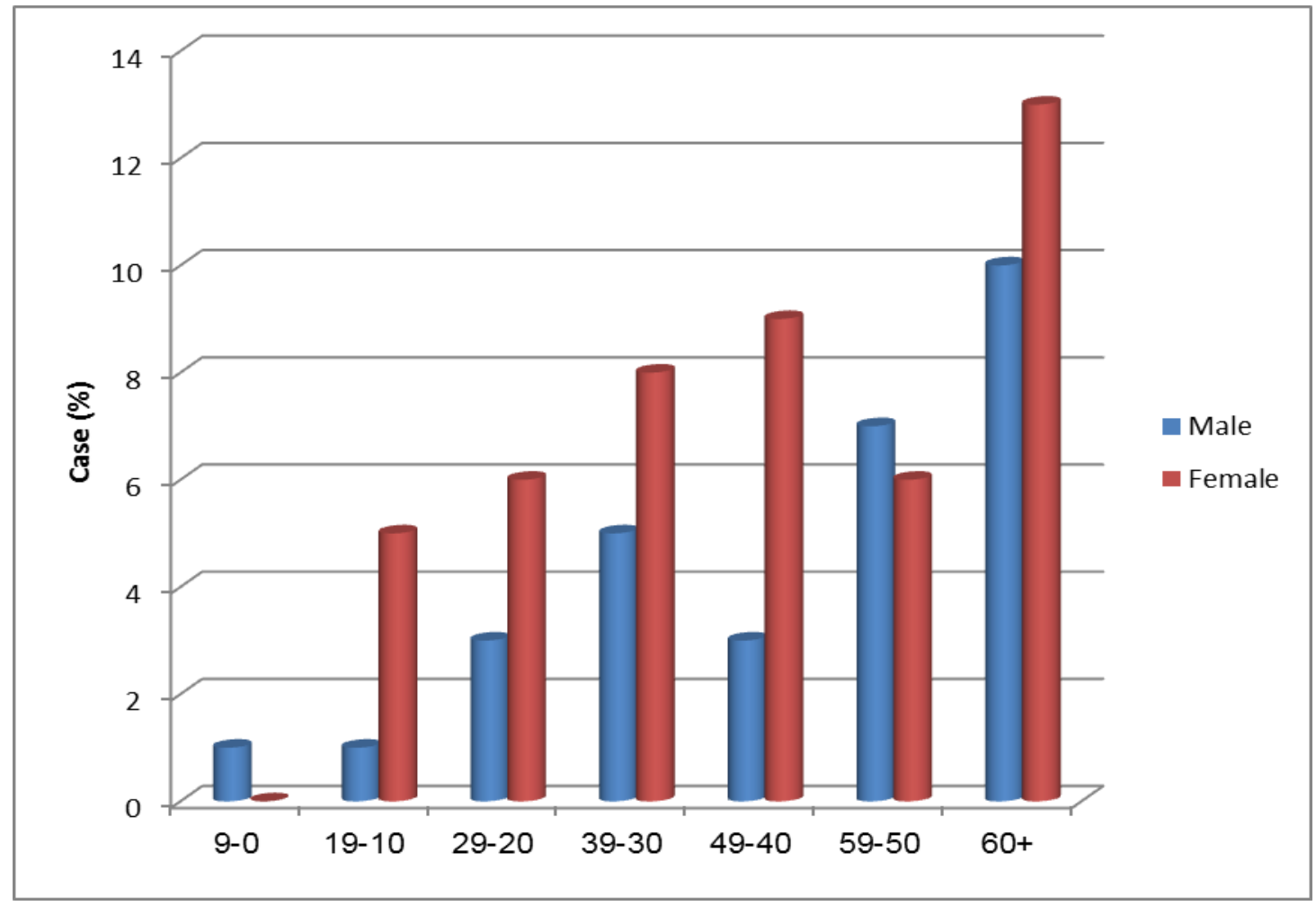

Figure 3: Distribution of $\boldsymbol{H}$. pylori positive patients according to age and sex 
Hayfa A. Hussein

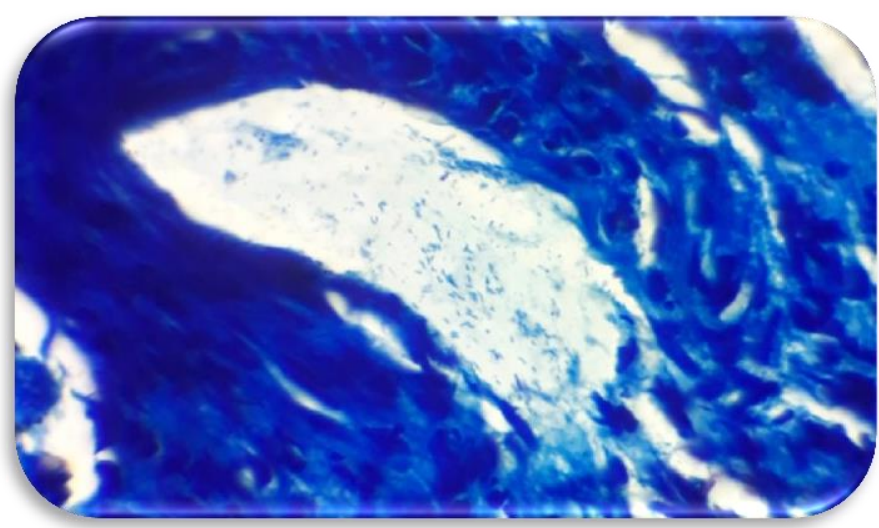

Figure 4: Antral gland demonstrating severe density of Helicobacter pylori (Giemsa stain X1000)

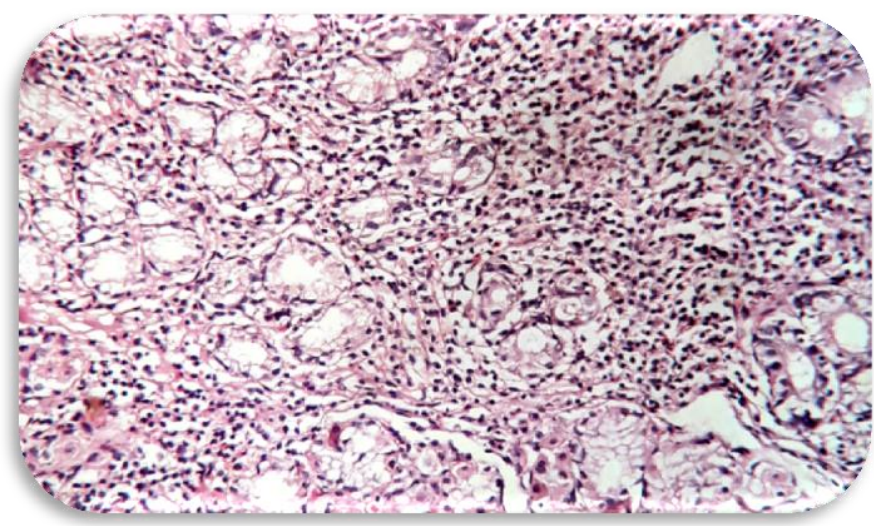

Figure 5: Chronic inflammation of the antral mucosa (severe grade of mononuclear cell infiltration), (H\&E X100)

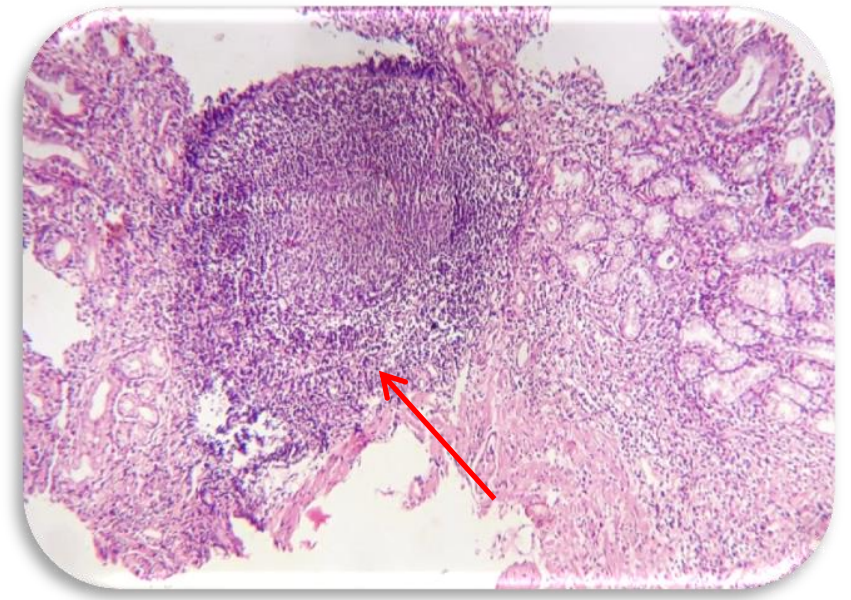

Figure 6: Lymphoid follicle formation in a severely inflamed antral mucosa (H\&E X40)
Evaluation of Chronic Gastritis in Endoscopic..

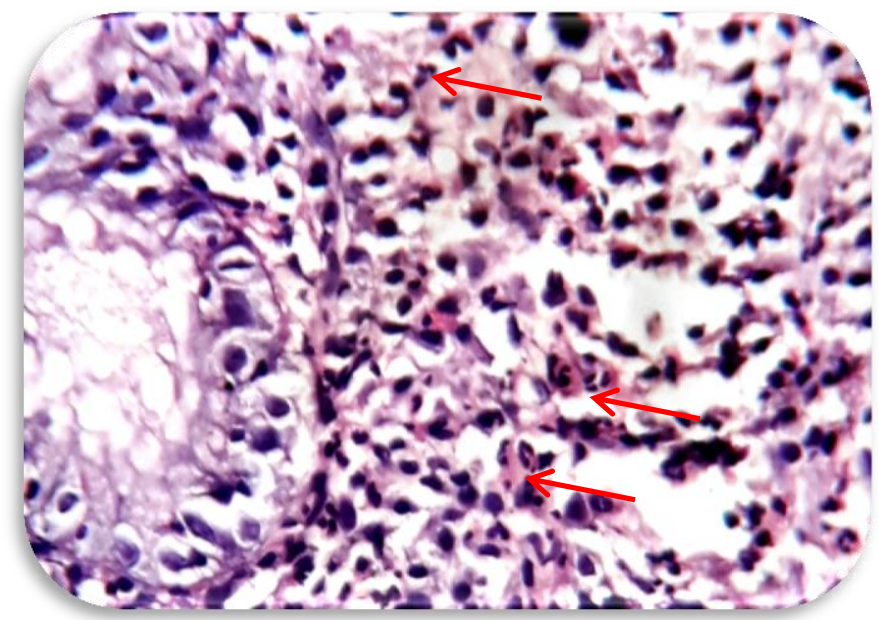

Figure 7: Antral mucosa with active inflammation (moderate grade of neutrophilic infiltration), (H\&E $\mathrm{X} 400)$.

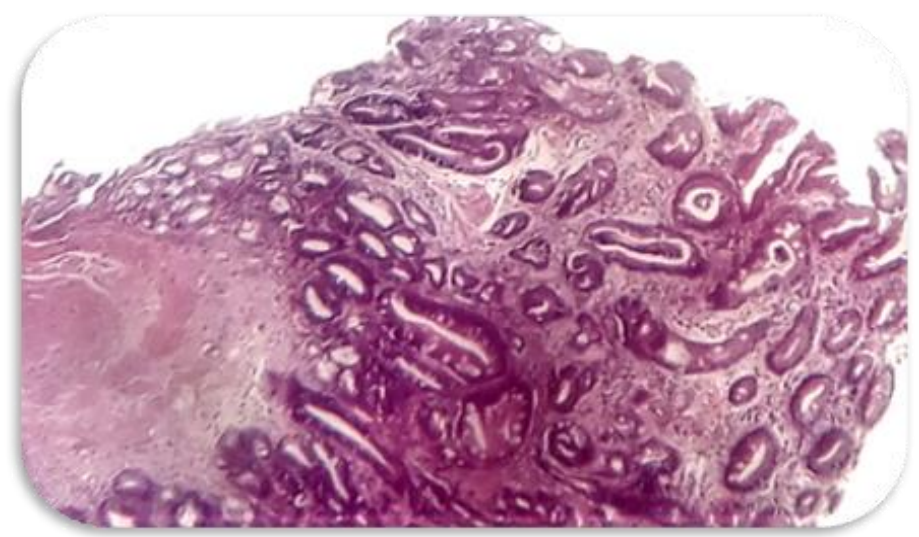

Figure 8: Moderate glandular atrophy of the antral mucosa (H\&E X40)

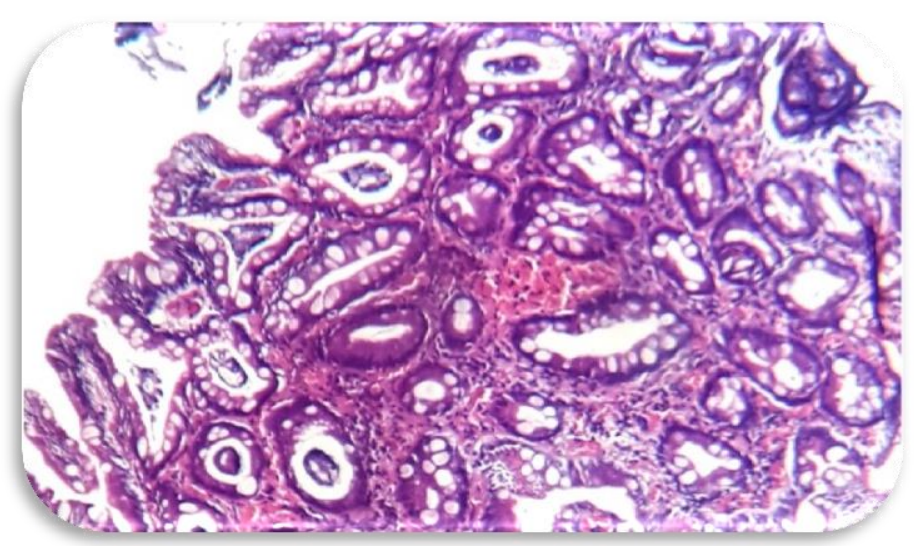

Figure 9-: Antral mucosa with severe intestinal metaplasia

(H\&E X100) 


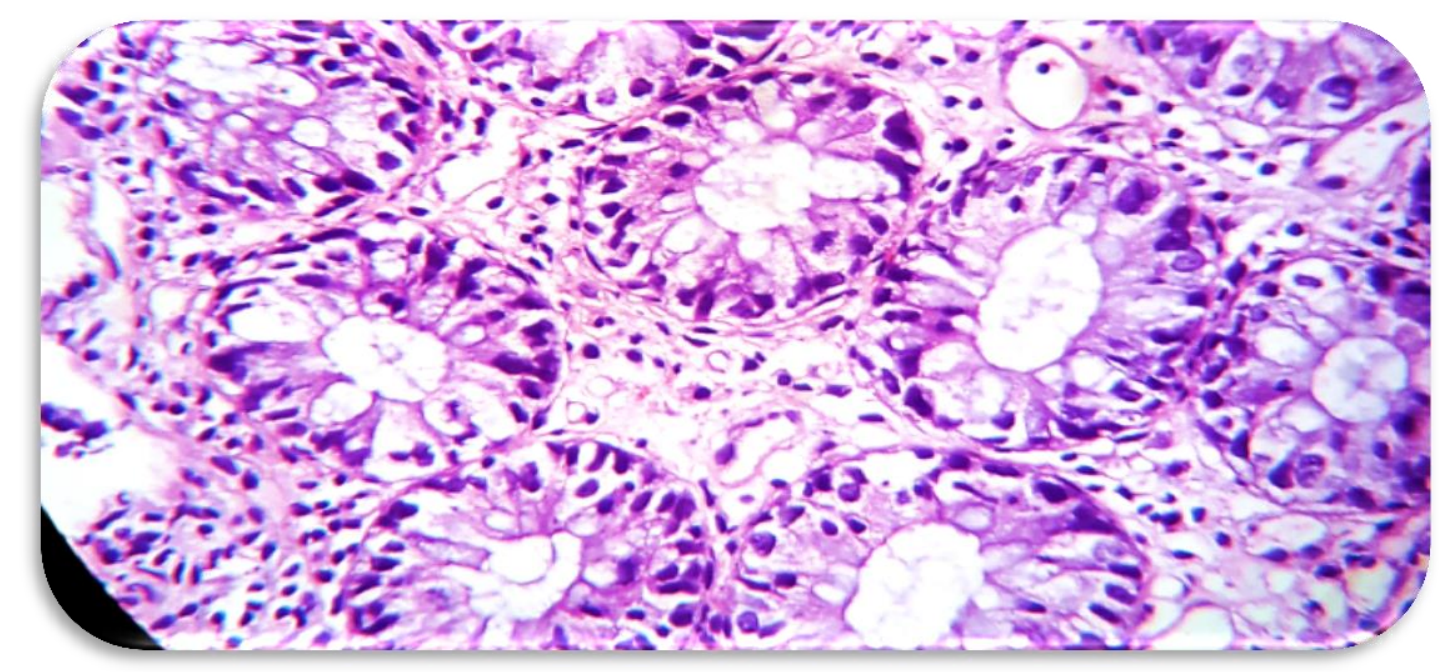

Figure 10: Antral glands with severe dysplastic changes (H\&E X400).

Table 2 : Association between $\boldsymbol{H}$. pylori status and histological parameters of chronic gastritis

\begin{tabular}{|c|c|c|c|c|}
\hline \multirow{2}{*}{ Parameters } & \multirow{2}{*}{$\begin{array}{l}\text { No. of } \\
\text { cases }\end{array}$} & \multicolumn{2}{|c|}{ H. pylori } & \multirow{2}{*}{ P-value } \\
\hline & & Positive & Negative & \\
\hline $\begin{array}{c}\text { Mononuclear cell } \\
\text { infiltration }\end{array}$ & 100 & $77(77 \%)$ & $23(23 \%)$ & $0.000 *$ \\
\hline Neutrophilic activity & 84 & $77(91.7 \%)$ & $7(8.3 \%)$ & $0.000 *$ \\
\hline Glandular atrophy & 22 & $17(77.3 \%)$ & $5(22.7 \%)$ & $0.011^{* *}$ \\
\hline Intestinal metaplasia & 14 & $10(71.4 \%)$ & $4(28.6 \%)$ & $0.109 * * *$ \\
\hline Dysplasia & 9 & $6(66.7 \%)$ & $3(33.3 \%)$ & $0.317 * * *$ \\
\hline
\end{tabular}

*: $\quad$ Very highly significant $(p<0.001)$

$* *$ : $\quad$ Significant $(p<0.05)$

$* * *$ : $\quad$ Not significant $(p>0.05)$

\section{DISCUSSION}

In the present study, chronic gastritis was noticed in a wide age group ranging from 9-85 years with a mean age of 42.7 years which is more or less consistent with other studies where the mean age was 47 years, ${ }^{10-13}$ and 48 years in another one ${ }^{14}$. However chronic gastritis was reported in an older age group in another previous study with a mean of 65.8 years ${ }^{15}$.

In this study an increase in the rate of $H$. pylori infection with increasing age (60 years and above)was observed which is in agreement with 
the results of other studies ${ }^{16-18}$ On the other hand 3 cases of chronic gastritis were recorded in children 10 years and below, $2(66.6 \%)$ of them showed no evidence of $H$. pylori, which was inconsistent with a previous study that showed an increased rate of $H$. pylori infection in children ${ }^{19}$. Probably, the low number of children patients involved in this study has affected the proper assessment of H.pylori infection rate in this age group.

A predominance of females having chronic gastritis has been noticed in this study with a M:F ratio of 1:1.3 which is in line with the study of Maharjan et al, in which M:F ratio was $1: 1.07^{15}$. On the contrary a higher M:F ratio was observed in many previous studies carried out by Chen et $\mathrm{al}^{20}$ Pruthi et $\mathrm{al}^{21}$ and Park et $\mathrm{al}^{22}{ }^{22}$ where they reported a M:F ratio of 1.8: 1, 2.3:1 and 2.8:1 respectively.

In the same respect, females were found to have a higher rate of $H$. pylori infection than males, which is comparable to the result of a previous study ${ }^{15}$ However, such a finding is not in line with the findings of others where males were found to have the higher rate of $H$. pylori infection ${ }^{11,14,21}$.

In the current study, the clinical symptoms the patients complaining of were variable, on the top of the list was abdominal pain mainly epigastric (46\%) followed by dyspepsia (17\%). Such results are consistent with that of a previous study which recorded these symptoms in (92\%) and (42.3\%) of cases respectively ${ }^{15}$. On the contrary, dyspepsia was the commonest presenting clinical symptom (33.3\%), followed by abdominal pain $(22.2 \%)$ in the study carried out by Pruthi et al ${ }^{21}$.

Gastric antrum was the site of endoscopic biopsy in the present study, as well as in the studies conducted by Garg et $\mathrm{al}^{11}$. Park et $\mathrm{al}^{22}$. and Dhakhwa et $\mathrm{al}^{23}$. Antral gastritis was the commonest endoscopic finding in this series $(66 \%)$, which is comparable to another study where antral gastritis represented the main form of gastritis. ${ }^{(10)}$ However other studies showed antral ulcer and erosion as the major endoscopic findings ${ }^{15,21}$.

In this series, H. pylori was identified in (77\%) of cases which is similar to the study conducted by Latif et $\mathrm{al}^{24}$, as well as in parallel with the results of Kalifehgholi et $\mathrm{al}^{25}$, Kumar et $\mathrm{al}^{26}$, and Abdul
Jabbar $^{27}$, that showed H. pylori in $86.8 \%, 78 \%$ and $75.3 \%$ of cases respectively. However higher $H$. pylori positive results were observed in the studies conducted by Hassan et $\mathrm{al}^{10}$, and Pourakbari et $\mathrm{al}^{28}$, which were $93.7 \%$ and $95 \%$ respectively. On the other hand, the result of this study is relatively high when compared with the results of Pruthi et $\mathrm{al}^{21}$, and Dhakhwa et $\mathrm{al}^{23}$, that displayed $H$. pylori in only $47 \%$ and $44 \%$ of cases respectively. The variation in the results above may be attributed to biopsy sampling, where multiple biopsies may be needed to improve results ${ }^{15}$, in addition, the use of special stain (e.g Giemsa) and immunostain are helpful for better detection of $H$. pylori ${ }^{29,30}$. However poor identification of $H$. pylori may be affected by a prior treatment with proton pump inhibitors or antimicrobial agents ${ }^{15}$. In this respect, another biopsy from the corpus is advisable to obtain positive results for $H$. pylori $i^{31,32}$.

Mononuclear cell infiltration formed the major histological variable in the present study, since it was encountered in all cases $(100 \%)$ which is similar to the studies conducted by others ${ }^{11,19,22,33}$. More than half of cases $(56 \%)$ showed moderate grade of mononuclear cell infiltration, while severe grade was found in $(27 \%)$ of cases and the mild one was restricted to $(17 \%)$ of cases only. These results were comparable to those of others ${ }^{19,22,33}$. Moreover $\mathrm{H}$. pylori was detected in $(77 \%)$ of cases with mononuclear cell infiltration which is regarded statistically as a very highly significant result $(P<0.001)$ and that is consistent with a previous study ${ }^{15}$. In the same connection, as the grade of mononuclear cell infiltration was higher, the possibility of $H$. pylori detection was more and with increased density. This is consistent with the results of other studies ${ }^{11,19,34}$, however it is inconsistent with the study of Udoh et al that found no association between the grade of mononuclear cell infiltration and density of $\mathrm{H}$. pylori ${ }^{14}$. In addition, the 4 cases of those having severe mononuclear cell infiltration with lymphoid follicles formation also displayed $H$. pylori in all of them which is compatible with the study of Dhakhwa et $\mathrm{al}^{23}$. However other studies found $\mathrm{H}$. pylori in about half of the cases with lymphoid follicles ${ }^{21,35}$. The importance of lymphoid follicles formation lies in being a characteristic feature of chronic $H$. pylori infection and the absence of the 
organism in such cases is more in favour of being missed by the examiner, or the infection being eradicated ${ }^{8}$.

Active inflammation represented by neutrophilic infiltration in the lamina propria or inside the glandular lumina was observrd in $(84 \%)$ of cases which is in line with the study conducted by Park et al, in which the result was $(78.7 \%)^{22}$. However, the result in the present study outnumbered that observed in in a previous one which showed only $(33.6 \%)$ of cases having neutrophilic activity. ${ }^{(15)}$ On the other hand, neutrophilic infiltration was noticed in all $H$. pylori positive cases which is compatible with the study of Dhakhwa et $\mathrm{al}^{23}$, while it was present in $(40.7 \%)$ of $H$. pylori positive cases in the study of Maharjan et $\mathrm{al}^{15}$. Neutrophilic infiltration was shown to be a sensitive indicator for the presence of $H$. pylori and disappears following the treatment of infection ${ }^{36}$.

In this study a very highly significant association was found between neutrophilic infiltration and the presence of $H$. pylori $(\mathrm{P}<0.001)$. This is comparable to other studies in this concern ${ }^{11,23,37}$. In the current study $7(8.3 \%)$ cases were found to have neutrophilic infiltration, and they were negative for $H$. pylori. Here of the many possible etiological factors, Crohn's disease may be considered, in addition to drug or alcohol induced and bile reflux gastritis ${ }^{8}$.

Atrophic changes of the mucosa were found in $(22 \%)$ of cases in the present study. This is relatively higher than that of Garg et al study which showed atrophy in (12.3\%) of cases ${ }^{11}$. Most of the cases of atrophy were seen in patients $>50$ years of age which is in agreement with other studies $^{15,21,38}$. Moreover $17(77.3 \%)$ cases of atrophic gastritis were also positive for $H$. pylori that was more or less consistent with the result of Pruthi et al which was $62.5 \%{ }^{21}$ Likewise a significant association was found between atrophy and the presence of $H$. pylori $(P<0.05)$, which is in contrast with the findings of others where the association was statistically insignificant ${ }^{11,15}$.

Intestinal metaplasia was encountered in $(14 \%)$ of cases which is consistent with Hassawi study which recorded this change in $15 \%$ of cases $^{39}$. However our result is higher than that recorded by Dhakhwa et al in which intestinal metaplasia was found in only $5 \%$ of cases $^{23}$. On the other hand, a higher rate was found in the study of Al- Nuaimy et al in which $23 \%$ of cases showed intestinal metaplasia ${ }^{16}$. The latter may be attributed to the fact that the use of special stain for mucin could improve the diagnostic rate of intestinal metaplasia. In the same respect, biopsy taken from the area of incisura angularis is said to be of value concerning the detection of intestinal metaplasia which initially develops in this region ${ }^{40}$. There was no significant statistical association between $H$. pylori and intestinal metaplasia $(P>0.05)$. This finding is in parallel to what has been discussed else where ${ }^{15,23}$

Dysplasia was another important histological variable observed in this study. It has been mentioned to have resulted from exposure of gastric epithelium to free radicals damage and proliferative stimuli resulting from chronic inflammation which over time can lead to carcinoma ${ }^{6}$. This study revealed dysplasia in $9 \%$ of cases which is more or less consistent with the study of Hassan et al in which $6.4 \%$ of cases showed dysplastic changes ${ }^{10}$. However, the finding of this study is in disagreement with that of Al- Nuaimy et al where no dysplasia was recorded $^{16}$, despite the fact that both studies were carried out in the same locality. One reason for this discrepancy may be the compromised immunity of people in our study due to the poor conditions they passed through in the previous years which rendered them vulnerable to $H$. pylori infection and chronic inflammation, that could induce this change.

Although $H$. pylori may no longer be detected in cases of dysplasia as mentioned by Dobrilla et $\mathrm{al}^{41}$, the organism has been identified in 6 $(66.7 \%)$ out of the 9 cases of dysplasia in the present study. However this result is statistically insignificant as $\mathrm{P}$-value was $>0.05$. Chronic atrophic gastritis associated with severe dysplasia requires periodic endoscopic follow up to rule out the possibility of gastric cancer, since the improvement of endoscopic techniques made possible the early detection of mucosal changes that predict malignancy ${ }^{42}$. 


\section{CONCLUSIONS}

Histopathological study of endoscopic antral gastric biopsy is of value in detecting $H$. pylori and various histological changes of chronic gastritis.

- $\quad$ Statistically significant associations were found between $H$. pylori and each of : mononuclear cell infiltration, neutrophilic activity and glandular atrophy.

Dysplasia is an important histological change in chronic gastritis that requires endoscopic follow up to rule out the possibility of gastric cancer, and it is advisable to be incorporated in the visual analogue scale of the up- dated Sydney system.

\section{REFERENCES}

1-Owen DA. Gastritis and carditis. Mod Pathol. 2003; 16: 325- 41.

2-Goldblum JR, Lamps LW, Mckenney JK, et al. Rosai and Ackerman Surgical pathology Eleventh Edition, 2018, 530 -1.

3-Watari J, Chen N, Amenta PS, et al. Helicobacter pylori associated chronic gastritis, clinical syndromes, precancerous lesions, and pathogenesis of gastric cancer development. World J Gastroenterol. 2014; 20: 5461 -73.

4-Makola D, Peura DA, Crowe SE. Helicobacter pylori infection and related gastrointestinal diseases. J Clin Gastroenterol. 2007; 41: 548 -58. 5-Bini EJ. Helicobacter pylori and iron deficiency anemia: Guilty as charged. Am J Med. 2001; 111: $495-7$.

6-Kumar V, Abbas AK, Aster JC. Robbins and cotran pathologic basis of disease. Ninth Edition, 2015, 763-8.

7-Price AB. The Sydney system, histological division. J Gastroenterol Hepatol. 1991; 6: 20922.

8-Dixon MF, Genta RM, Yardley JH, et al. Classification and Grading of gastritis. The Up dated Sydney System. International Workshop on the Histopathology of Gastritis, Houston 1994. Am J Surg Pathol. 1996; 20: $1161-81$.

9-Rotimi O, Cairns A, Moayyedi $P$, et al. Histopathological identification of Helicobacter pylori: comparison of staining methods. J Clin Pathol. 2000; 53: 756 -9.
10- Hassan TMM, Al-Najjar SI, Al-Zahrani IH, et al. Helicobacter pylori chronic gastritis updated Sydney grading in relation to endoscopic findings and $H$. pylori IgG antibody: diagnostic methods. J Microsc Ultrastruct. 2016; 4: 167 -74.

11- Garg B, Sandhu V, Sood N, et al. Histopathological analysis of chronic gastritis and correlation of pathological features with each other and with endoscpic findings. Pol J Pathol. 2012; 163: 172 -8.

12- Aydin O, Egilmez R, Karabacak T, et al. Interobserver variation in histopathological assessment of Helicobacter pylori gastritis. World J Gastroenterol. 2003; 9: 2232 -5.

13- Mustapha SK, Ajayi NA, Nggada HA, et al. Endoscopic findings and the freguency of Helicobacter pylori among dyspeptic patients in Maiduguri, North-Eastern Nigeria. Highland Med Res J. 2007; 5: 78 -81.

14- Udoh MO, Obaseki DE. Histopathological evaluation of $H$. pylori associated gastric lesions in Benin city, Nigeria. East Afr Med J. 2012; 89: $408-13$.

15- Maharjan S, Ranabhat S, Tiwari M, et al. Helicobacter pylori associated chronic gastritis and application of visual analogue scale for the grading of the histopathological parameters in Nepal. Biomed J Sci \& Tech Res. 2017; $1: 28$ 34.

16- Al-Nuaimy WMT, Faisal HM: Endoscopical and histopathological interpretation of gastritis in Nineveh Province, Ann Coll Med Mosul, 2019; 41: $28-35$.

17- Graham DY, Malaty HM, Evans DJ, et al. Epidemiology of Helicobater pylori in an asymptomatic population in the United States: Effect of age, race and socioeconomic status. Gastroenterology. 1991; 100: 1495- 501.

18- Asaka $M$, Kimura $T$, Kudo $M$, et al. Relationship of Helicobacter pylori to serum pepsinogens in an asymptomatic Japanese population. Gastroenterology. 1992; 102: 760 -6. 19- Archila P, Tovar L, Ruiz M, et al. Histological characteristics of chronic gastritis reported in gastric biopsies from children aged 1 to 16 years at the Hospital Infantile de San Jose from September 2008 to September 2010. Rev Col Gastroenterol 2012; 27: 74 -8.

20- Chen XY, Liu WZ, Shi Y, et al. Helicobater pylori associated gastric diseases and lymphoid 
tissue hyperplasia in gastric antral mucosa. J Clin Pathol. 2002; 55: $133-7$.

21- Pruthi S, Nirupama M, chakraborti S, et al. Evaluation of gastric biopsies in chronic gastritis: Grading of inflammation by Visual Analogue Scale. Med J DY Patil Univ. 2014; 7: 463 - 7.

22- Park J, Kim MK, Park SM. Influence of Helicobacter pylori colonization on histological grading of chronic gastritis in Korean patients with peptic ulcer. Korean J Intern Med 1995; 10: 125 9.

23- Dhakhwa R, Acharya IL, Shrestha HG, et al. Histopathologic study of chronic antral gastritis. J Nepal Health Res Counc. 2012; 10: 57 - 60.

24- Latif A, Azadeh B. Helicobacter pylori gastritis in Qatar. A clinico- histopathological study. Qatar Med J. 2002; 11: 12 - 5.

25- Kalifehgholi M, Shamsipour F, Ajhdarkosh H, et al. Comparison of five diagnostic methods for Helicobacter pylori. Iran J Microbiol. 2013; 5:396401.

26- Kumar A, Bansal R, Pathak VP, et al. Histopathological changes in gastric mucosa colonized by $H$. pylori. Indian J Pathol Microbiol. 2006; 49: 352 -6.

27- Abdul Jabbar B. The demonstration of $H$. pylori in the gastroduodenal endoscopic biopsies by using different stains. A thesis submitted to the Iraqi Commission for Medical Specialization in Pathology, 1997.

28- Pourakbari B, Ghazi M, Mahmoudi S, et al. Diagnosis of Helicobacter pylori infection by invasive and noninvasive tests. Brazil J Microbiol. 2013; 44: 795 -8.

29- Cartun RW, Kryzmowski GA, Pedersen CA, et al. Immunocytochemical identification of Helicobacter pylori in formalin - fixed gastric biopsies. Mod Pathol. 1991; 4: 498 - 502.

30- Chan WY, Hui PK, Leung KM, et al. Coccoid froms of Helicobacter pylori in the human stomach. Am J Clin Pathol. 1994; 102: $503-7$.

31- Hunt $\mathrm{RH}$. $\mathrm{Hp}$ and $\mathrm{pH}$ : implications for the eradication of Helicobacter pylori. Scand $\mathrm{J}$ Gastroenteral suppl. 1993; 196: $12-6$.

32- Solcia E, Villani L, Luinetti $O$, et al. Proton pump inhibitors, entero chromaffin - like growth and Helicobacter pylori gastritis. Aliment Pharmacol Ther. 1993; 7: 25- 8.

33- Witteman EM, Mravunac M, Becx MJ, et al. Improvement of gastric inflammation and resolution of epithelial damage one year after eradication of Helicobacter pylori. J Clin Pathol. 1995; 48: 250 - 6.

34- Uhlig HH, Tannapfel A, Mossner J, et al. Histopathological parameters of Helicobacter pylori-associated gastritis in children and adolescents: comparison with findings in adults, Scand J Gastroenterol. 2003; 38: 701 - 6 .

35- Genta RM, Hammer HW, Graham DY. Gastric lymphoid follicles in Helicobacter pylori infection: frequency, distribution and response to triple therapy. Hum Pathol. 1993; 24: 577 - 83.

36- Xu XQ, Wang ZH, Liao JX, et al. Predictive value of neutrophil infiltration as a marker of Helicobacter pylori infection. World J Gastroenterol. 2012; 18: $5101-5$.

37- Zhang C, Yamada N, Wu YL, et al. Comparison of Helicobacter pylori infection and gastric mucosal histological features of gastric ulcer patients with chronic gastritis patients. World J Gastroenterol. 2005; 11: 976 - 81.

38- Schlemper RJ, van der Werf SD, Vandenbroucke JP, et al. Seroepidemiology of gastritis in Japanese and Dutch working populations: evidence for the development of atrophic gastritis that is not related to Helicobacter pylori. Gut. 1995; 37: $199-204$.

39- Hassawi BA, Khalil KH, Sharafadin ZA. Prevalence of intestinal metaplasia and dysplasia in infectious and non-infectious chronic gastritis. Int J Res Med Sci. 2015; 3: 2228 - 31.

40- Uedo N, Kanzaki H, Ishihara R. Endoscopic diagnosis of gastric intestinal metaplasia. Gastroenterol Endosc. 2014; 56: 1941 -52.

41- Dobrilla G, Benvenuti S, Amplatz S, et al. Chronic gastritis, intestinal metaplasia, dysplasia and Helicobacter pylori in gastric cancer: putting the pieces together. Ital J Gastroenterol. 1994; 26 : $449-58$.

42- Lauwers GY. Defining the pathologic diagnosis of metaplasia, atrophy, dysplasia and gastric adenocarcinoma. J Clin Gastroenterol. 2003; $36: 37-43$. 